\title{
You and $\mathrm{CO}_{2}$ : a Public Engagement Study to Engage Secondary School Students with the Issue of Climate Change
}

\author{
Jennifer A. Rudd ${ }^{1}$ (D) $\cdot$ Ruth Horry ${ }^{2}$ (I) $\cdot$ R. Lyle Skains ${ }^{3}$ (I)
}

Published online: 21 December 2019

(C) The Author(s) 2019

\begin{abstract}
School students are growing up in a world with a rapidly changing climate, the effects of which will become increasingly apparent during their lifetimes. We designed and pilot tested "You and $\mathrm{CO}_{2}$ ", a STEAM program designed to encourage students to reflect on their personal impact on the environment, while also appreciating their place within society to bring about positive societal change. Over three interlinked workshops, students analyzed the carbon footprints of some everyday activities, which they then explored in more detail through interacting with a bespoke piece of digital fiction, No World 4 Tomorrow. The program culminated with students producing their own digital fictions, allowing them the freedom to explore the themes from the previous workshops with a setting and focus of their choice. We reflect here on the experience of running the You and $\mathrm{CO}_{2}$ program and on the themes that emerged from the students' original digital fictions.
\end{abstract}

Keywords Education $\cdot$ Climate change $\cdot$ Digital fiction $\cdot$ STEAM $\cdot$ Climate change education

\section{Introduction}

Climate change poses a serious threat to our planet, which will only be mitigated through a reduction in carbon emissions. As citizens of the world, individuals each have a role to play, adjusting their behavior both to reduce personal carbon emissions and to fuel public pressure on bigger contributors like industry and government. We present preliminary findings from a pilot evaluation of a school-based STEAM (Science, Technology, Engineering, Arts, and Mathematics) program that aimed to encourage students to reflect on their individual roles as consumers and on their ability as members of a wider society to affect positive societal change. The program combined science- and arts-based approaches, including

Electronic supplementary material The online version of this article (https://doi.org/10.1007/s10956-019-09808-5) contains supplementary material, which is available to authorized users.

Jennifer A. Rudd

j.a.rudd@swansea.ac.uk

1 Energy Safety Research Institute, College of Engineering, Swansea University, Bay Campus, Fabian Way, Swansea SA1 8EN, UK

2 Department of Psychology, College of Human and Health Science, Swansea University, Singleton Campus, Swansea SA2 8PP, UK

3 School of Creative Studies and Media, Bangor University, Bangor LL57 2DG, UK interacting with and creating interactive digital fictions on the topic of climate change. Below, we outline our rationale for the approach before describing the program and evaluation methods more fully.

\section{The Need for Climate Change Engagement in Schools}

According to the recent Intergovernmental Panel on Climate Change (IPCC) special report, the world has already warmed by 1.1 degrees Centigrade compared with pre-industrial levels (IPCC 2018). At the current rate of warming, scientists predict significant changes to the natural world and the ability of humans to inhabit the world (Mora et al. 2017). Global warming can only be limited by reducing global greenhouse gas emissions (IPCC 2014). Nation states have a major role to play in the effort to reduce emissions, as formally acknowledged in the signing of the 2015 Paris Agreement. However, individual citizens also have the obligation to reduce their personal carbon emissions. Dietz et al., for example, estimated that household carbon emissions in the USA could be reduced by $5-12 \%$ if householders adopted a range of behavioral changes (e.g., line drying of clothing, reducing thermostat settings) (Dietz et al. 2009). While some activities have obvious direct emissions associated with them (e.g., driving, home energy usage), other activities produce much less obvious, indirect emissions, which arise from the production of goods and services (Wiedmann and Minx 2008; Berners-Lee 2008). 
For example, the average individual is likely to be unaware of the carbon emissions associated with the foods they choose to eat, with their internet usage, or with the clothes they choose to wear (Gombiner 2011; Kim and Neff 2009). Achieving the carbon reduction goals necessary for limiting climate change thus requires knowledge, political will, and action from the world's citizens.

For individuals to understand the need for behavior change, education and engagement with the science of climate change is key; Lester et al. demonstrated in 2006 that K-12 students with more education in climate science expressed increased engagement in climate change-related activism than others (Lester et al. 2006). While individuals of all ages would benefit from increased engagement with climate science, there are several good reasons to develop interventions that are targeted at school children. First, the youngest citizens of our world will have to live with the consequences of climate change for longest and will therefore be the most heavily impacted by those consequences (Jorgenson et al. 2019). This fact is increasingly recognized by children and adolescents themselves, leading to unprecedented levels of activism from young people; indeed, over the past year, children have played a major role in raising global awareness of climate change and its consequences. The School Strike movement, for example, has grown from one Swedish teenager to an estimated 1.4 million students globally as of May 2019 (Evensen 2019) and 7.6 million people as a whole as of September 2019 (350.org 2019).

Second, behavior change becomes increasingly difficult as habits become more firmly entrenched (Webb et al. 2009). Consequently, many attempts to change behavior, across a broad range of domains (e.g., diet, exercise, smoking), fail completely or end in relapse (Polivy and Herman 2002). Adolescents are not likely to have formed many of the habits that contribute heavily to household carbon emissions (Dietz et al. 2009), presenting the opportunity to intervene before carbon-intensive habits are formed.

Third, the education system provides a unique environment for public engagement with science. The nature of schooling means that it is much more practical to develop programs that span multiple sessions than it is for typical science outreach and public engagement activities, which tend to be delivered as standalone events. Programs delivered in a school environment can therefore be more ambitious, providing more scope for combining multiple approaches in an effort to increase engagement.

The current political and social environment also makes the current program, and others like it, timely. In the UK, there is considerable appetite among teachers and students alike for greater coverage of climate change in the school curriculum (Taylor 2019). At present, climate change tends to be covered in individual subjects such as science and geography, though there are recent calls for climate change to be integrated as a core theme throughout the curriculum (Rayner 2019). Furthermore, a recent review of the education system within Wales argued that a fundamental goal of education should be to develop "ethical, informed citizens who understand and consider the impact of their actions when making choices and acting" (Donaldson 2015). The You and $\mathrm{CO}_{2}$ program was developed to allow students to explore ideas about their own role as a consumer and as a member of society in tackling the urgent global issue of climate change.

\section{Climate Change Education Framework}

A consensus emerging from recent studies of climate change education (CCE) is that effective educational programs should cross traditional disciplinary boundaries, and encourage students to reflect on the broader social and moral context of climate change (e.g., Ardoin et al. 2018; Cantell et al. 2019; Gayford 2002; Jorgenson et al. 2019; Pruneau et al. 2001; Wise 2010). Gayford (Gayford 2002) notes that teachers tend to teach in silos: chemistry in a chemistry lesson, geography in a geography lesson, etc. They reportedly want to "maintain the integrity of their subject rather than be involved in extensive interdisciplinary teaching" (p. 1191). Climate change, however, is a multidisciplinary problem, with a need for multidisciplinary solutions, as expounded by the research detailed in this section. Therefore, we developed our program using combined science- and arts-based approaches.

We have used the following studies to develop a theoretical framework for our You and $\mathrm{CO}_{2}$ program, each of which makes recommendations for the development of new CCE: Cantell et al. (Cantell et al. 2019), Ardoin et al. (Ardoin et al. 2018), Wise (Wise 2010), (Pruneau 2001), Jorgenson et al. (2019) and (Gayford 2002). The link between these studies, aside from the theme of environmental education or CCE, was that educational programs need to have (i) an interdisciplinary approach, and (ii) go beyond the acquisition of knowledge so that students are encouraged to think about what they have learnt in a broader social and moral context.

A significant proportion of the research on CCE supports and recommends interdisciplinary and multiliteracies approaches, as climate change is an interdisciplinary problem stretching across chemistry, geography, social science, politics, economics, psychology, health, and more. Ardoin et al.'s 2018 work demonstrates that CCE can be used to develop the following literacies: systems thinking (holistic approaches to analysis), critical thinking (objectively evaluating facts to form judgments), decision-making research skills (synthesizing data into knowledge for recommendations and action), and science-process skills (observing, communicating, classifying, inferring, measuring, and predicting). Therefore, any new program developed should incorporate opportunities for students to learn these skills. Likewise, Pruneau et al. (2001) and Wise (Wise 2010) both recommend 
an interdisciplinary approach to CCE; Wise in particular recommends supporting the teachers through professional development activities, specifically regarding interdisciplinarity. She suggests that science and social studies departments could work together to teach climate change as "disciplinary divisions ... appear to generate barriers to providing students with comprehensive instruction about climate change" (p 305).

In addition, the need to stimulate hope for the future echoes throughout CCE studies. Pruneau et al. (Pruneau et al. 2001) recommend "future education" where students are encouraged to re-imagine their future; by doing so, students are empowered to imagine changes in their lives and explore the consequences of those changes. Pruneau also recommends a critical socio-constructivism approach where CCE is "presented as a generalized discussion" (p. 134) wherein instructor and students engage in a group chat on the topic. Jorgenson et al. (2019) recommends that CCE focus on "local, tangible and actionable" (p. 165) endeavors that can be achieved by individuals. This would then inspire intergenerational education where the student would bring home CCE from school and therefore influence the behaviors of their caregivers. Jorgenson's recommendations are to:

1. Move CCE beyond a focus on individual behavioral change; teach about systemic change.

2. Develop participatory CCE to engage students in multiactor networks of NGOs, climate scientists, community groups, state agencies, and renewable energy firms.

3. Teach about technological and social innovation currently occurring in the world; this engenders hope, which in turn leads to meaningful action.

4. Develop new narratives to encourage long-term engagement with CCE.

Cantell et al. (2019) extensively reviewed CCE resources and developed the Bicycle Model of climate change education. The model summarizes the key components of CCE, using the image of a bicycle as a visual representation of those components: a frame consisting of values, worldview, and identity; pedals providing action impulsion to the wheels of knowledge and thinking skills; a saddle of motivation and participation; operational barriers braking the system; and handlebars steering toward a future orientation as hope and emotions light the road ahead. Cantell et al.'s model also makes the following key recommendations to those developing new CCE materials:

1. Emphasize that humans can change society; engage students in joint positive action.

2. Encourage students to think about the role of human beings as consumers, and therefore the cause of environmental problems.

3. Stimulate hope and compassion.
4. Combine science-based teaching with critical thinking so that students can assess technological advances within a broader social context.

This model thus creates a holistic, interdisciplinary approach to CCE that engages students both in developing skills across an array of STEAM subjects while also contextualizing climate change in a broader sociological sense. As such, we have used these recommendations to evaluate the efficacy of our workshops (see the "Discussion" section below).

\section{Engaging Students Through Arts-Based Approaches}

The You and $\mathrm{CO}_{2}$ project adopted a multiliteracies approach (Cope and Kalantzis 2009; Skains 2019), incorporating digital literacy, interactivity, creative writing, game design, discussion, and group and individual work to engage students with the topic of climate change. The first workshop focused on the chemistry of climate change and provided the opportunity for students to explore their own carbon footprints. The second and third workshops incorporated bibliotherapy with digital texts and expressive writing through game design and coding to allow the students to explore ideas around personal responsibility, climate change, and the consequences of climate change in a novel and engaging way. Bibliotherapy employs purposeful reading as a psychological intervention for treatment of clinical issues (Pardeck 2014); here, we apply it to the more technological medium of interactive, hypertext, digital narratives, or "Twine games." Likewise, expressive writing uses writing narratives as a therapeutic intervention in cognitive behavioral therapy in order to address emotional or mental issues (Mugerwa and Holden 2012; Victoria Field and Thompson 2006); in this program, we adapt this concept to computer-based interactive narrative design. Both bibliotherapy and expressive writing have the potential for broader psychological interventions; here, we use them as a means to engage students more deeply with the core themes of the You and $\mathrm{CO}_{2}$ project — namely, their own role as a citizen of the world in limiting carbon emissions.

To increase the immersiveness of the bibliotherapy and expressive writing components of the You and $\mathrm{CO}_{2}$ program, we used the technology of digital fiction: fiction that is written specifically to be read from a digital device (e.g., computer, tablet). Digital fiction makes full use of the digital environment to incorporate elements (e.g., branching plot lines, moving images) that would be impossible in an analogue format (see (Alice Bell et al. 2010) for a full definition). The use of digital fiction in bibliotherapy and expressive writing is relatively new, so evaluation is limited (although see (Ensslin et al. 2016) for a study on digital fiction as a tool for teenage body image bibliotherapy). However, our working hypothesis is that playing and coding digital fiction narratives will embed the core themes from the You and $\mathrm{CO}_{2}$ project on multiple 
cognitive levels, thus creating deeper engagement with the themes covered in the program.

\section{Methods}

\section{Sample}

Secondary school students from two schools in Wales, UK, participated in the workshops. In school 1, eighty-five students from three year, 9 classes (ages 13-14) participated. School 1 was a large comprehensive school in South Wales with around 2000 students from 11 to 18 years of age. The school serves a relatively affluent area, with a below-average proportion of students eligible for free school meals. The proportion of students with special educational needs is below average for Wales. Around 25\% of students are from a minority ethnic background (Estyn report, 2018).

Ninety-five students from school 2 participated. The students were in years 8, 9, and 10 (aged 12 to 15). School 2 was an independent school in North Wales with around 200 students aged 9 to 18 years. As a fee-paying school, most students come from relatively affluent backgrounds. While the majority of students live in the surrounding areas, around one-third of the students live internationally and board at the school during term time. Very few of the students have special educational needs. Around $23 \%$ of the students are from minority ethnic backgrounds, with around one-third of students speaking English as an additional language (Estyn report, 2019).

To protect student anonymity, we did not record the gender or age of participants; however, the gender balance across each of the classes was approximately even.

\section{Workshops}

The program involved three workshops, which were delivered by the research team. In school 1 , the workshops were each roughly one month apart. In school 2 , the workshops took place in much more rapid succession, with the entire program delivered over three days. Each workshop is described fully below. Briefly, workshop 1 focused on the chemistry of climate change and the carbon emissions associated with everyday activities that were relevant to the students' own lives. Workshops 2 and 3 introduced the digital fiction component of the program. In workshop 2, students played through a custom-written digital fiction, No World 4 Tomorrow, while in workshop 3, students created their own digital fiction on the theme of climate change.

\section{Workshop 1}

Workshop 1 was designed to ensure that students had a basic understanding of the role of carbon dioxide $\left(\mathrm{CO}_{2}\right)$ in climate change and to encourage students to reflect on the carbon footprints associated with their everyday activities. After reflecting on our experiences running workshop 1 at school 1 , we made several changes to the session before delivering it at school 2. Below, we focus on the revised workshop delivered in school 2, highlighting key points of difference for the sessions in school 1. Lesson plans for schools 1 and 2 can be found in the online supplementary materials.

Workshop 1 began with group discussions probing students' understanding of the term "carbon footprint." Students volunteered types of human activity (e.g., energy, transport) that contribute to carbon footprints. In the next part of the session, we aimed to bring to life the process by which $\mathrm{CO}_{2}$ is created through hands-on activities. Alongside instruction about the chemical reactions involved (see Eq. 1), students created three-dimensional models of methane and oxygen molecules using Bunchems (Velcro-style balls of different colors that can be stuck together), which they converted into $\mathrm{CO}_{2}$ and water molecules (see Fig. 1).

$$
\mathrm{CH}_{4}+2 \mathrm{O}_{2}->\text { Energy }+\mathrm{CO}_{2}+\mathrm{H}_{2} \mathrm{O}
$$

The remainder of the session focused on the carbon footprints associated with everyday activities (e.g., traveling by different modes of transport, consuming different breakfast foods) that would be relevant to the students' own lives. Carbon footprints for each activity were taken from the book How Bad Are Bananas? (Berners-Lee 2008) and the Tesco supermarket website. To help the students visualize the carbon emissions associated with each activity, they were shown an inflated balloon, which they were instructed represented $16 \mathrm{~g}$ of $\mathrm{CO}_{2}$. The number of balloon was then used as units for the remaining activities and discussions - for example, traveling one mile in a car was described as equivalent to 44 balloons of $\mathrm{CO}_{2}$.

In school 2, students calculated their own carbon footprints for the first two hours of their day using the reference document in the online supplementary materials. Time allowing, the students were then grouped together and asked to reduce the group's carbon footprint by one-third. In school 1, as a whole class activity, students guessed the number of balloons of $\mathrm{CO}_{2}$ associated with a number of different activities.

\section{Workshop 2}

In workshop 2, we aimed to encourage students to reflect on the importance of living in an environmentally sensitive way through immersion in an interactive story entitled No World 4 
Fig. 1 Bunchems models of the reaction by which methane and oxygen (left) react to form $\mathrm{CO}_{2}$ and water (right)
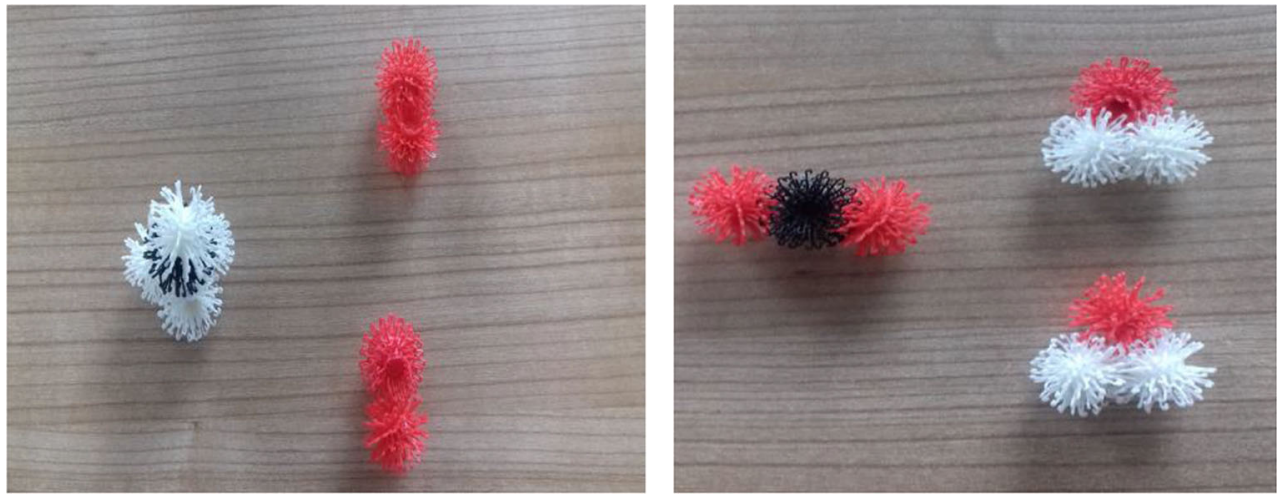

Tomorrow, which was written specifically for this project by Lyle Skains (freely available at www.youandco2.org). Throughout the story, readers are able to make choices about how the characters behave - from choosing the food that they consume, to how they travel, to the way in which they engage with their community concerning societal issues around sustainability. The actions that the reader makes affect the direction of the story, ultimately leading to one of six possible endings. These endings include being passive and letting disaster happen, accepting personal responsibility but eschewing dramatic action, actively engaging in accelerating the oncoming disaster, engaging and becoming an eco-warrior, profiting from the oncoming disaster, and becoming an activist, thus saving the world. Additional nuance was given to each ending depending on choices made throughout the story, indicating how small, everyday choices can lead to varying levels of personal impact on global environment.

The lesson plan for workshop 2 can be found in the online supplemental materials. At the beginning of the workshop, students were introduced to the concept of digital fiction by looking through a number of published examples. Digital fiction was defined as "Fictional stories created ON or FOR digital devices, which would lose important elements if taken out of digital media" (Alice Bell et al. 2010). The students then played through the story as a whole class. Students made collective decisions about characters' names and actions. For some decisions, where there was a clear majority for one option, that option was chosen. For other decisions, where there was no clear consensus, the students were encouraged to debate the possibilities until they could agree on a decision.

Following the whole class play through, the students worked in small groups to discuss the following questions: How does this story relate to the topics covered in workshop 1 ? How similar are the characters' experiences and choices to your own experiences and choices? How can you relate this story to your own experiences and habits?

In the remaining time, each student was given individual access to the digital fiction to play through the story by themselves or in pairs. They were encouraged to find as many different endings as they could by making different decisions for the characters.

Finally, as homework, students were asked to prepare for workshop 3 by planning a storyline for their own digital fiction. They were encouraged to think about details such as the kind of world their story would be set in; whether it would be set in the past, present, or future; who the characters would be; and what would happen, including the possibility for multiple plotlines.

\section{Workshop 3}

The aim of workshop 3 was for students to develop their own ideas by creating their own digital fictions. We took a deliberately non-prescriptive approach, allowing the students to focus on whatever themes they chose (as long as it related to climate change and/or carbon footprints). Students were introduced to Twine, an open-source program for digital storytelling (https://twinery.org) and were directed to online tutorials housed on the project website. These tutorials begin with accessing the program and creating a new hypertext project, getting familiar with the architecture of the software, and learning the fundamentals of coding for digital functionality. Students desiring added functionality (such as custom colors, user input, images, sound, and points systems) can work their way through the more advanced tutorials that incorporate HTML, JavaScript, and CSS coding. In school 2, where more time was allocated to the session, the students were given additional in-person tutorials by the third author. Following this introductory segment, workshop 3 was relatively unstructured, with students free to work on their digital fictions at their own pace, while members of the research team circulated the room to answer queries and provide support.

\section{Evaluation}

We evaluated the program in three key ways. First, we reflected on our own experiences of administering the program, which was facilitated through structured conversations 
with teachers in school 1 . We reflected on both technological and logistical challenges with delivering the workshops, as well as the extent to which the students appeared to be engaged with the content.

Second, we informally examined the themes in the participants' original digital fictions. Students were free to submit or decline to submit their own work to the project website. In total, 85 stories were submitted (55 from school 1; 30 from school 2). A full qualitative analysis of the contents of these stories is beyond the scope of the current paper. However, we make some informal observations here regarding recurring themes and ideas that came through, insofar as these guided our evaluation of the project and its impact on the participants.

Third, we developed the five-item Attitudes to Carbon Footprint Reduction (ACFR) scale (see Table 1). We began by generating a large set of items, adapting items from other scales of individual responsibility in other domains, and supplementing these with original items. We then filtered out items with the lowest face validity, items with language that we felt might be difficult to comprehend for children from our target age group to comprehend, and items that appeared to measure slightly different concepts (e.g., attitudes toward governmental responsibility for climate change). The result was a five-item scale with high face validity.

For each item, participants selected one of four possible responses: strongly agree, agree, disagree, or strongly disagree. We ensured that we had a mix of positively and negatively worded items to minimize acquiescence bias (Cronbach 1960). For positively worded items, scores were awarded as follows: strongly agree, 3 points; agree, 2 points; disagree, 1 point; strongly disagree, 0 points. For negatively worded items, the scoring was reversed. Item scores were summed to give a total attitude score for each participant, which could vary from 0 to 15 . Higher scores represent a more positive attitude toward carbon footprint reduction.

The ACFR scale was administered at four time points: prior to workshop 1 and at the end of workshops 1, 2, and 3. Prior to completing the scale, participants were provided with the following instructions, designed to minimize socially desirable responding: "The sentences below show the kinds of things people sometimes say about climate change and carbon dioxide. Think carefully about whether you agree or disagree with each sentence, then circle the answer that best fits your feelings. There are no right or wrong answers. No-one other than the researchers will see your answers, and the researchers will not know which answers are yours, so please be completely honest." To protect the participants' anonymity, the participants generated a codename, which they wrote on the top of each scale. This procedure allowed us to match up participants' responses across time points without making the data personally identifiable. Participants could opt out of providing scale data and were informed that they could do so by returning a blank questionnaire or by attaching a post-it note to a completed questionnaire.

\section{Results}

On the whole, the workshops were well received by the students and the teachers. Here, we reflect on the logistical and situational challenges that we faced, and how these informed the steps we took to refine the workshops. We also highlight issues that readers may wish to consider if adapting the You and $\mathrm{CO}_{2}$ program, or using a similar approach, for implementation.

\section{Reflections on Program Delivery}

In school 1, large class sizes (around 30-35 students) meant that the attention of the students had to be captured and held or widespread chatter would break out. The initial structure of workshop 1 (i.e., in school 1) was largely instructor-led, with minimal student-to-student interaction. Answers to questions were sought on a hands-up basis, which created a situation where more outgoing and confident students engaged but the attention of the other students was lost. After discussions with the teachers who observed workshop 1 , we refined the session to increase interactivity and increase student-tostudent interaction. These refinements created a more engaging and inclusive workshop which worked very effectively in school 2. In particular, the group work component of the revised workshop, in which students worked together to find ways to reduce their group's carbon footprint by one-third, helped students to identify where their biggest $\mathrm{CO}_{2}$ emissions were coming from. It also provided valuable roleplaying experience of carbon reduction negotiations, mirroring, albeit in

Table 1 The five item Attitudes to Carbon Footprint Reduction (ACFR) scale

\begin{tabular}{ll}
\hline Item number & Item wording \\
\hline 1 & There is no point in trying to change my behavior, as nothing I do will have any real effect on climate change \\
2 & If everybody makes changes to their lifestyles and behavior, we can reduce the effects of climate change \\
3 & It is my responsibility to reduce the amount of carbon dioxide that I put into the environment \\
4 & Changing my behavior is pointless, as we cannot really know what the climate will be like in the future \\
5 & It is very important for me to act in a way that reduces my impact on the environment and on the climate \\
\hline
\end{tabular}


a simplified way, the conversations that will happen in governments as they move toward legislating for a low-carbon economy.

Workshops 2 and 3 required technical equipment, including access to computers with internet connectivity. We had hoped to have one computer per student, but consistently faced technical and logistical challenges that resulted in several students sharing one computer. Slow internet speeds also caused significant issues in school 1 , which limited the ability of some students to play through the story individually in workshop 2. We also found that the website through which the digital fiction could be accessed was blocked, creating delays in beginning workshop 2 for the first classes in both schools. Any teachers or researchers interested in implementing this approach should liaise closely with the technical staff to discuss bandwidth capabilities and computer access in advance of the session, as well as ensuring that any required websites are unblocked. If possible, technical support should be on hand before and during the session to ensure that the session goes smoothly. In our experience, technical issues not only increased time pressure of the workshops, but they also created discipline issues as students grew impatient.

We began workshop 2 by reading through the digital fiction as a whole class activity. We did so to guarantee that all participating students would experience the story in full at least once. However, we found that the effectiveness of the group reading varied as a function of class size. In smaller classes (15-25 students), the students enjoyed the somewhat chaotic nature of making group decisions and debating about the available story options. However, in larger class sizes, this approach led to general disruption and it became difficult to regain control to move to the next part of the story. In school 1 (which had the larger class sizes), the teachers suggested that the workshop might progress more smoothly if the students each read the digital fiction alone. We will be testing this approach in future iterations of the project, which we hope will lead to improved classroom behavior and engagement.

Prior to workshop 3, students in school 1 had been asked to plan their own stories as homework, but only one class (of three) had done so. Due to the tight turnaround between workshops 2 and 3 at school 2, homework was not feasible. This provided us with an informal insight into the impact of preparation on the delivery on workshop 3. Overall, we found that the session in which the students came prepared with some ideas worked more effectively, as students were able to make the most of their time, therefore producing more complete stories than in the other groups. Indeed, in classes that had not prepared ahead of the session, the most frequent query from students was along the lines of "I don't know what to write about". We would strongly recommend that any teachers and/or researchers who aim to implement these types of creative workshops into their climate change curriculum ensure that the activity is supported by homework assignments and/ or additional planning sessions.

On a technical level, none of the students struggled using Twine. Some students were more adventurous than others, while others created more traditional, linear stories. The former incorporated customized elements such as colors, user input boxes, images, and sound files; all students incorporated at least the basic level of Twine coding for links between passages and some aspect of choice-based branching structures. Informally, we observed that younger students (year 8, ages 12-13) tended to use the software quite creatively, incorporating colored words, images, and a mechanism for readers to personalize the story by inputting their own charactersthough their stories tended to be quite linear. The older students generally had stories with more complex storylines and multiple decision pathways.

\section{Themes Emerging from Students' Stories}

To provide an indication of whether students had reflected on the issues covered in the first two workshops of the program, we informally analyzed the students' original digital fictions to identify key themes. In school 1, a recurring theme was tourism with key decision points focusing on modes of travel from low-carbon options (e.g., cycling, busses) to higher carbon options (e.g., flying). Plastic waste and pollution were also common themes, though these were not explicitly addressed in workshops 1 and 2. However, there have been considerable national and global conversations around plastic pollution in the last two years. For example, in October 2017, BBC's Blue Planet II sparked a national plastics debate by highlighting the devastating impact of plastic pollution on marine ecosystems. Recently, governments in many countries have legislated to ban and restrict the production and sale of single-use plastic products (Treasury 2019; Economist 2019).

In school 2, a recurring theme was food choices, with an emphasis on veganism and low-meat diets. Particularly among younger students, messages tended to be quite stark: veganism or death. There was even one story involving vegan penguins! The carbon footprint associated with different breakfast foods was discussed in workshop 1 and food choices also featured in No World 4 Tomorrow, the digital fiction introduced to students in workshop 2, though we were careful not to advocate for veganism. It is likely that some of the messages that students were incorporating reflect recent media messaging around the environmental impact of meat production. As a key example, a recent study in The Lancet (Willett et al. 2019) was covered by many major UK news outlets (e.g., The Guardian, BBC News). In addition, Veganuary, a charity inspiring people to try vegan for January, is gaining in popularity in the UK.

Students in school 2 more frequently incorporated information directly from workshop 1 , as well as technical and 
narrative elements from workshop 2's reading of No World 4 Tomorrow, into their stories than students in school 1. For example, the balloons of $\mathrm{CO}_{2}$ units were used by some students in school 2, but by none in school 1; likewise, many groups in school 2 wanted to incorporate the cycling links ${ }^{1}$ and Moon-colony themes, though none in school 1 did. This is unsurprising given the much shorter delay between workshops in school 2 (one day each) than in school 1 (one month each).

Collectively, our informal analysis of the content of the digital fictions suggested that the students had reflected on the general themes from workshops 1 and 2, but that they had also drawn extensively on their broader understanding of environmental issues.

\section{Attitudes Toward Carbon Footprint Reduction Scale}

Before analyzing the survey data, we first examined the ACRF scale's internal reliability by calculating Cronbach's $\alpha$. Generally speaking, a scale is considered to have good internal reliability if $\alpha$ is equal to or greater than .80 , and acceptable reliability if $\alpha$ is equal to or greater than .70 . We calculated $\alpha$ for both schools separately, using all valid time point 1 data. For school 1, $\alpha=.82$; for school $2, \alpha=.76$. Thus, scale reliability was acceptable for both schools.

The data were analyzed using a mixed effects regression, which is recommended for longitudinal data and is also robust to missing data (Garcia and Marder 2017). Because there were substantial differences in the way that the program was delivered between the two schools, we analyzed each dataset separately rather than pooling them in a single analysis. We first created a baseline model in which ACFR scores were predicted from the random effect of participant only. We then created a second model in which the fixed effect of time point was added. Rather than treating time as a linear variable, which would have been inappropriate given the uneven spacing of the time points, we treated time point as a factorial variable. The change in goodness-of-fit of the two models was assessed. A statistically significant change in model fit (indicated by a $p$ value smaller than .05 ) indicated that ACFR scores differed between at least one pair of time points, in which case we conducted pairwise comparisons, applying the Tukey method for $p$ value adjustment with multiple comparisons. Analyses were conducted using the lme4 package (Bates et al. 2015) and the emmeans package (Russell Lenth et al. 2019) for R (R Core Team 2019).

Inferential statistics can be seen in Table 2; the beta values represent the estimated change in ACFR scores between the

\footnotetext{
${ }^{1}$ A type of link used in hypertext fiction that does not lead to another passage, but rather changes the text of the link itself (for instance, players of NW4T click to choose lunch options). Twine's cycling links are made possible by a JavaScript macro; thus, these students learn to incorporate more advanced coding in their stories.
}

pair of time points included in each comparison, expressed in the original scale units. Thus, a beta value of 1.00 would indicate a mean change of 1 point on the 15-point ACFR scale. Estimated marginal means are shown in Fig. 2. In the text, we provide a descriptive overview of the findings. In both schools, there was a statistically significant effect of time point on ACFR scores. Our data suggest that participating in the You and $\mathrm{CO}_{2}$ program was associated with some small, positive changes in attitudes toward carbon footprint reduction. Both schools showed a general increase in ACFR scores over time, though the pattern was slightly different across the two schools (Fig. 3). In school 1, the largest difference occurred between the beginning and end of the first workshop. In school 2, the changes were more gradual, with the largest difference between the beginning of the first workshop and the end of the final workshop. Taken together, these results indicate that participants may have had somewhat more positive attitudes toward reducing their carbon footprints scores after participating in the program than before participating.

There are some important caveats to bear in mind when interpreting these data. First, and most importantly, we do not have data from a control group. Thus, it is impossible to disentangle any true effects of participation in the program from confounding variables. For example, participants may have responded in the way that they thought was desired by the researchers, slightly increasing their ACFR scores over time. Media coverage of climate change in the UK also increased dramatically over the duration of the program in school 1, largely in response to social movements such as the Youth Strikes for Climate and high-profile protests by the activist group Extinction Rebellion. Exposure to the media may have accounted for at least some of the changes in ACFR scores in school 1; however, it is unlikely to have contributed much to changes in ACFR scores at school 2, as the program was delivered over a period of a few days. Moving forward, it will be crucial to conduct controlled trials to draw stronger conclusions on the impact of the program on students' attitudes toward reducing their carbon footprints.

A second important caveat is that the size of the change in ACFR scores was small-less than one point on a 15point scale. It is an open question as to whether such small changes in attitudes (assuming that these scores do, indeed, accurately capture underlying attitudes) will actually lead the participants to take steps to reduce their carbon footprints. Though attitudes do predict behavior, the relationship is not perfect; there are many barriers (psychological and practical) to behavior change that an attitude change may be insufficient to overcome (Frantz and Mayer, 2009). An important direction for future research will be to attempt to measure intended and actual behavior change, allowing us to establish whether participation in the You and $\mathrm{CO}_{2}$ program has any real-world impact on behavior. 
Table 2 Inferential statistics for ACFR scores

\begin{tabular}{|c|c|c|c|c|c|c|c|}
\hline & & \multicolumn{3}{|c|}{ School 1} & \multicolumn{3}{|c|}{ School 2} \\
\hline \multicolumn{2}{|c|}{ Overall effect of time } & \multicolumn{3}{|c|}{$\chi^{2}(3)=9.27, p=.026^{*}$} & \multicolumn{3}{|c|}{$\chi^{2}(3)=18.01, p=.001^{* *}$} \\
\hline \multicolumn{2}{|c|}{ Time points in comparison } & $\beta$ & $z$ & $p$ & $\beta$ & $z$ & $p$ \\
\hline TP1 & TP2 & 0.62 & 2.58 & $.049 *$ & 0.20 & 0.80 & .85 \\
\hline TP1 & TP3 & 0.23 & 0.91 & .80 & 0.68 & 2.89 & $.02 *$ \\
\hline TP1 & TP4 & 0.60 & 2.45 & .07 & 0.93 & 3.85 & $.001 * *$ \\
\hline TP2 & TP3 & -0.40 & 1.57 & .40 & 0.48 & 1.95 & .21 \\
\hline TP2 & TP4 & -0.02 & 0.07 & .99 & 0.73 & 2.90 & $.02 *$ \\
\hline TP3 & TP4 & 0.38 & 1.51 & .43 & 0.25 & 1.04 & .73 \\
\hline
\end{tabular}

\section{Discussion}

The You and $\mathrm{CO}_{2}$ program adopts a multidisciplinary approach to CCE. By doing so, we have been able to break out of siloed teaching and allow students the opportunity to think more broadly about the social and moral context of climate change and its consequences. Through this STEAM program, the science of climate change has been taught in a way that is relevant and societally engaged, bridging the gap between the classroom and the wider world. In addition, the program has allowed students to apply knowledge of numeracy, English language, storytelling, computer programming, and chemistry to a pressing global problem that will have a profound impact on their lives. We reflect here on how successfully the You and $\mathrm{CO}_{2}$ program has met the recommendations laid out in the "Introduction" section of this paper.

\section{Emphasize that Humans Can Change Society; Engage Students in Joint Positive Action}

The first activity students are asked to do (in workshop 1) is to account for their carbon footprint for their day's first two hours; they are then led through a series of activities and discussions re-imagining their future based on changes to these habits. In completing this activity, students are presented with the idea that humans can change society, and they engage in joint positive action through working in groups. Workshop 1 also focuses on "local, tangible and actionable" endeavors (Jorgenson 2019, p.165), where students can make immediate changes to their lives following the workshop.

This emphasis on positive change continues in workshop 2, where students engage in a digital fiction with branching storylines. The digital fiction, No World 4 Tomorrow, incorporates storylines exploring various avenues of action, from individual to societal (as well as no action at all). Each decision made in the digital fiction has a consequence, either for the main character or for the society around the main character, further emphasizing students' ability to change society either singly or through joint positive action. In workshop 3, this lesson is extended through their own digital fictions; whether or not students are working on a single digital fiction in a group, they nonetheless create them in a classroom environment, sharing their stories with one another, and discussing their creations.
Fig. 2 A simplified excerpt of the backend structure of No World 4 Tomorrow, showing the multiple pathways that the digital fiction takes dependent on choices made

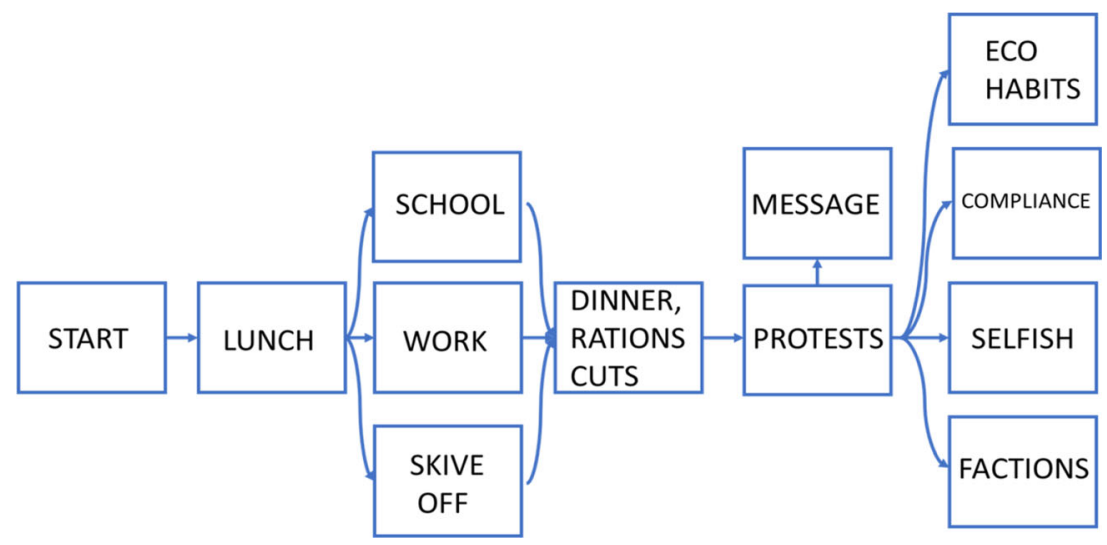



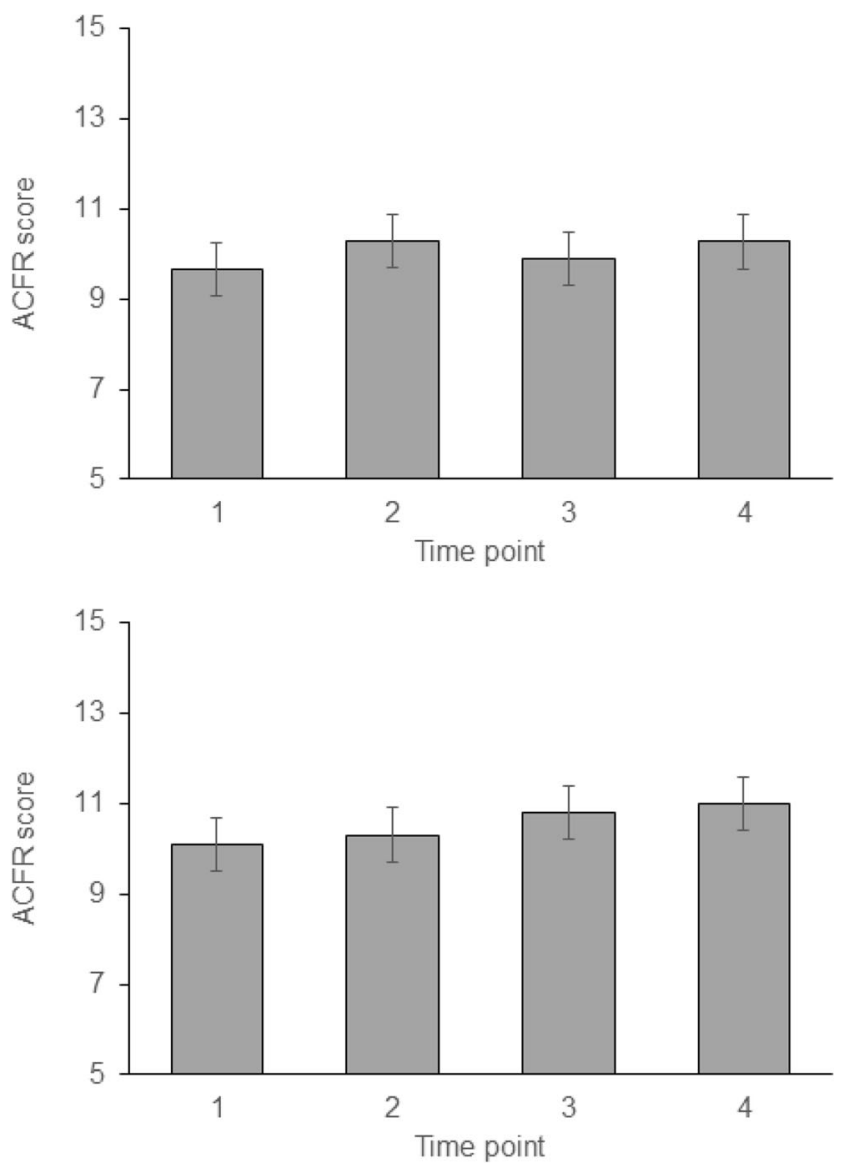

Fig. 3 Estimated marginal mean Attitude to Carbon Footprint Reduction scale scores from school 1 (top) and school 2 (bottom). Error bars represent $95 \%$ confidence intervals

\section{Encourage Students to Think About the Role of Human Beings as Consumers, and Therefore the Cause of Environmental Problems}

Workshop 1's carbon footprint activity drives this point home quite sharply; this is reflected in the stories they create in workshop 3, where they often question their own consumer choices (such as the environmental effects of wearing makeup, or of manufacturing a soccer ball). These stories also demonstrate achievement of a key learning outcome: for students to develop critical thinking regarding climate change. They show they are able to take the basic concept of carbon footprint from their breakfast and school commute routines, and extrapolate it to other areas of their life, such as shopping, recreation, and health.

\section{Stimulate Hope and Compassion}

Workshop 3 gives students the opportunity to write their own digital fictions and these provide the strongest evidence that the You and $\mathrm{CO}_{2}$ program stimulates hope and compassion (Cantell et al. 2019, Jorgenson et al
2019). Some students wrote about being leaders of cities/countries/the EU and having decision-making powers that would mitigate climate change. Other students wrote about social justice; one digital fiction addressed mining for make-up components and the injustice of the miners' pay vs the sale price of the make-up product. Another story highlighted how climate change will affect poor countries in the Southern hemisphere more than rich countries in the North. You and $\mathrm{CO}_{2}$ 's approach-advancing awareness of climate change then encouraging open-ended thinking about how to address the problem-incorporates hope and compassion at a foundational level. Digital fiction places readers in an interactive environment, encouraging them to think about their choices; in creating their own digital fictions, students place themselves in positions of power in order to explore facets of the crisis and propose their own solutions. This in and of itself stimulates hope.

\section{Combine Science-Based Teaching with Critical Thinking so that Students Can Assess Technological Advances Within a Broader Social Context}

Workshop 1 also encourages students to develop scienceprocess skills, as recommended by Ardoin et al. (2018). They learn about the carbon cycle and the chemistry underlying it, and are encouraged throughout all three workshops to research other causes contributing to and effects resulting from climate change. Workshop 2's digital fiction creates global society on a microscale (a small settlement on the moon), complete with political factions, technological issues, and personal concerns, so that students can grasp the very large, globally complex issue of climate change through a smaller metaphorical lens. In particular, one storyline involves the development of new technology that could change the lives of a select few characters in the story, leaving others to an uncertain fate, encouraging students to question technological innovation and its effect on society.

The combination of all three workshops introduces the science of climate change on a personal level, then encourages students to approach the issue from a personal, actionable perspective. Done in a classroom setting, these activities encourage group interaction and feedback, and students often work together to design solutions to climate-related aspects of their own lives. Likewise, the open, creative nature of designing interactive digital fictions in workshop 3 encourages students to seek out answers to their scientific how and why questions, performing research to enhance their creative work. Overall, the You and $\mathrm{CO}_{2}$ project pilot offers a cohesive, integrated STEAM approach that meets Cantell et al.'s recommendations as outlined in their Bicycle Model of CCE. 


\section{Conclusions}

We have developed a STEAM program to engage young people with the social and moral context of climate change and to encourage them to consider their own role as a consumer and as a member of a wider society. Our multidisciplinary approaches allowed the students the chance to explore themes around climate change in a novel and engaging way. This was reflected in the digital fictions written by the students, which had diverse storylines but featured common themes for reducing one's carbon footprint, including travel, food consumption, and plastic waste. A crucial next step for this project will be to run larger, controlled trials that will allow us to measure the impact of the program on knowledge, attitudes, and behavior.

Acknowledgements We would like to acknowledge the Recycling Carbon (www.recyclingcarbon.wordpress.com) outreach activity from the Energy Safety Research Institute, Swansea, UK, which inspired workshop 1.

Dr. David Aldous is thanked for helpful discussions throughout the project. We would also like to thank reviewers 1 and 2 and Prof. K. Crippen for helpful conversations which improved this manuscript.

Authors' Contributions All authors contributed to the study conception and design. Material preparation for workshop 1 was carried out and delivered by Jennifer A. Rudd. Material preparation for workshops 2 and 3 was carried out by R. Lyle Skains. Workshops 2 and 3 were delivered by Jennifer A. Rudd and R. Lyle Skains respectively. The attitude survey was designed and analyzed by Ruth Horry. The first draft of the manuscript was written by Jennifer A. Rudd and Ruth Horry and all authors commented on previous versions of the manuscript. All authors read and approved the final manuscript.

Funding Information We thank the Welsh Crucible program, Swansea University, and Bangor University for financial support. We would like to thank the Reducing Industrial Carbon Emissions (RICE) research operations funded by the Welsh European Funding Office (WEFO) through the Welsh Government for funding. We would also like to thank Prof. Andrew R. Barron for support.

\section{Compliance with Ethical Standards}

Ethics All procedures performed in studies involving human participants were in accordance with the ethical standards of the institutional and/or national research committee (Department of Psychology Ethics Committee, College of Human and Health Sciences, Swansea University, Project 1368) and with the 1964 Helsinki declaration and its later amendments or comparable ethical standards. Informed consent was obtained from all individual participants included in this study.

Conflict of Interest The authors declare that they have no competing interests.

Open Access This article is licensed under a Creative Commons Attribution 4.0 International License, which permits use, sharing, adaptation, distribution and reproduction in any medium or format, as long as you give appropriate credit to the original author(s) and the source, provide a link to the Creative Commons licence, and indicate if changes were made. The images or other third party material in this article are included in the article's Creative Commons licence, unless indicated otherwise in a credit line to the material. If material is not included in the article's Creative Commons licence and your intended use is not permitted by statutory regulation or exceeds the permitted use, you will need to obtain permission directly from the copyright holder. To view a copy of this licence, visit http://creativecommons.org/licenses/by/4.0/.

\section{References}

350.org (2019) 7.6 million people demand action after week of climate strikes. 1.org. Accessed 04/10/2019 2019.

Alice Bell, A. E., Ciccoricco, D., Rustad, H. K., Laccetti, J. M., Pressman, J. (2010). A [S] creed for digital fiction. Electronic Book Review.

Ardoin, N. M., Bowers, A. W., Roth, N. W., \& Holthuis, N. (2018). Environmental education and K-12 student outcomes: a review and analysis of research. The Journal of Environmental Education, 49(1), 1-17. https://doi.org/10.1080/00958964.2017.1366155.

Bates, D., Mächler, M., Bolker, B., \& Walker, S. (2015). Fitting Linear Mixed-Effects Models Using. Journal of Statistical Software, 67(1).

Berners-Lee, M. (2008). How bad are bananas?: The carbon footprint of everything: Profile Books Ltd.

Cantell, H., Tolppanen, S., Aarnio-Linnanvuori, E., \& Lehtonen, A. (2019). Bicycle model on climate change education: presenting and evaluating a model. Environmental Education Research, 25(5), 717-731. https://doi.org/10.1080/13504622.2019.1570487.

Cope, B., \& Kalantzis, M. (2009). "Multiliteracies": new literacies, new learning. Pedagogies: An International Journal, 4(3), 164-195. https://doi.org/10.1080/15544800903076044.

Cronbach, L. J. (1960). Essentials of psychological testing (2nd ed.). New York: Harper \& Row.

Dietz, T., Gardner, G. T., Gilligan, J., Stern, P. C., \& Vandenbergh, M. P. (2009). Household actions can provide a behavioral wedge to rapidly reduce US carbon emissions. Proceedings of the National Academy of Sciences, 106(44), 18452-18456. https://doi.org/10. 1073/pnas.0908738106.

Donaldson, G. (2015). Successful futures: independent review of curriculum and assessment arrangements in Wales, Crown Copyright, OGL. Ever more countries are banning plastic bags. (2019, The Economist.

Ensslin, A., Skains, L., Riley, S., Haran, J., Mackiewicz, A., \& Halliwell, E. (2016). Exploring digital fiction as a tool for teenage body image bibliotherapy. Digital Creativity, 27(3), 177-195. https://doi.org/10. 1080/14626268.2016.1210646.

Evensen, D. (2019). The rhetorical limitations of the \#FridaysForFuture movement. Nature Climate Change, 9(6), 428-430. https://doi.org/ 10.1038/s41558-019-0481-1.

Frantz, C. M., \& Mayer, F. S. (2009). The Emergency of Climate Change: Why Are We Failing to Take Action? Analyses of Social Issues and Public Policy, 9(1), 205-222.

Garcia, T. P., \& Marder, K. (2017). Statistical Approaches to Longitudinal Data Analysis in Neurodegenerative Diseases: Huntington's Disease as a Model. Current Neurology and Neuroscience Reports, 17(2).

Gayford, C. (2002). Controversial environmental issues: a case study for the professional development of science teachers. International Journal of Science Education, 24(11), 1191-1200. https://doi.org/ $10.1080 / 09500690210134866$.

Gombiner, J. (2011). Carbon footprinting the Internet. Consilience: The Journal of Sustainable Development, 5(1), 119-124.

IPCC (2014). Climate change 2014: synthesis report. Contribution of Working Groups I, II and III to the Fifth Assessment Report of the Intergovernmental Panel on Climate Change. In R. K. P. a. L. A. M. e. Core Writing Team (Ed.), (pp. 151). IPCC, Geneva, Switzerland. 
IPCC (2018). Global warming of 1.5 degrees centigrade. IPCC Special Report.

Jorgenson, S. N., Stephens, J. C., \& White, B. (2019). Environmental education in transition: a critical review of recent research on climate change and energy education. The Journal of Environmental Education, 50(3), 160-171. https://doi.org/10.1080/00958964. 2019.1604478 .

Kim, B., \& Neff, R. (2009). Measurement and communication of greenhouse gas emissions from U.S. food consumption via carbon calculators. Ecological Economics, 69(1), 186-196. https://doi.org/10. 1016/j.ecolecon.2009.08.017.

Lenth, R., Singmann, H., Love, J., Buerkner, P., \& Herve, M. (2019). emmeans: Estimated marginal means, aka Least Squares Means.

Lester, B. T., Ma, L., Lee, O., \& Lambert, J. (2006). Social activism in elementary science education: a science, technology, and society approach to teach global warming. International Journal of Science Education, 28(4), 315-339. https://doi.org/10.1080/ 09500690500240100.

Mora, C., Dousset, B., Caldwell, I. R., Powell, F. E., Geronimo, R. C., Bielecki, C. R., et al. (2017). Global risk of deadly heat. Nature Climate Change, 7, 501. https://doi.org/10.1038/nclimate3322 https://www.nature.com/articles/nclimate3322\#supplementaryinformation.

Mugerwa, S., \& Holden, J. D. (2012). Writing therapy: a new tool for general practice? The British Journal of General Practice, 62(605), 661-663. https://doi.org/10.3399/bjgp12X659457.

Pardeck, J. A. (2014). Using books in clinical social work practice: a guide to bibliotherapy. New York: Routledge.

Polivy, J., \& Herman, C. P. (2002). Causes of eating disorders. Annual Review of Psychology, 53(1), 187-213. https://doi.org/10.1146/ annurev.psych.53.100901.135103.

Pruneau, D. L., Linda, Vrain, E., Gravel, H., Borque, W., \& Langis, J. (2001). People's ideas about climate change: a source of inspiration for the creation of educational programs. Canadian Journal of Environmental Education, 6, 121-138.

Rayner, A. (2019). Labour to make climate change core part of school curriculum. https://labour.org.uk/press/labour-make-climatechange-core-part-school-curriculum/. Accessed 01/07/2019 2019.

R Core Team (2019). R: A language and environment for statistical computing. https://www.R-project.org/.

Skains, R. L. (2019). Teaching digital fiction: integrating experimental writing and current technologies. Palgrave Communications, 5(1), 13-10. https://doi.org/10.1057/s41599-019-0223-z.
Taylor (2019). Teachers want climate crisis training. The Guardian. https://www.theguardian.com/environment/2019/jun/21/teacherswantclimate-crisis-training-poll-shows.

The Economist (2019). Ever more countries are banning plastic bags. https:/www.economist.com/graphic-detail/2019/07/24/ever-morecountries-are-banning-plasticbags.

Treasury, H. (2019). Overview of consultation on plastic packaging tax. https://consult.defra.gov.uk/environmental-quality/plasticpackaging-tax/.

Victoria Field, G. B., Kate Thompson (2006). Writing works: a resource handbook for therapeutic writing workshops and activities. London: Jessica Kingsley Publishers.

Webb, T. L., Sheeran, P., \& Luszczynska, A. (2009). Planning to break unwanted habits: Habit strength moderates implementation intention effects on behaviour change. The British Journal of Social Psychology, 48(3), 507-523. https://doi.org/10.1348/ $014466608 \times 370591$.

Wesman, A. G. (1960). Essentials of Psychological Testing. Lee J. Cronbach. Harper, New York, ed. 2, 1960. xxi + 650 pp. Illus. \$7. Science 131(3408), 1209-1210

Wiedmann, T., \& Minx, J. (2008). A definition of carbon footprint. Ecological Economics Research Trends, 1, 1-11.

Willett, W., Rockström, J., Loken, B., Springmann, M., Lang, T., Vermeulen, S., Garnett, T., Tilman, D., DeClerck, F., Wood, A., Jonell, M., Clark, M., Gordon, L. J., Fanzo, J., Hawkes, C., Zurayk, R., Rivera, J. A., de Vries, W., Majele Sibanda, L., Afshin, A., Chaudhary, A., Herrero, M., Agustina, R., Branca, F., Lartey, A., Fan, S., Crona, B., Fox, E., Bignet, V., Troell, M., Lindahl, T., Singh, S., Cornell, S. E., Srinath Reddy, K., Narain, S., Nishtar, S., \& Murray, C. J. L. (2019). Food in the Anthropocene: the EAT\&\#x2013;<em $>$ Lancet $</$ em $>$ Commission on healthy diets from sustainable food systems. Lancet, 393(10170), 447-492. https://doi.org/10.1016/S0140-6736(18)31788-4.

Wise, S. B. (2010). Climate change in the classroom: patterns, motivations, and barriers to instruction among Colorado science teachers. Journal of Geoscience Education, 58(5), 297-309. https://doi.org/ 10.5408/1.3559695.

Publisher's Note Springer Nature remains neutral with regard to jurisdictional claims in published maps and institutional affiliations. 